\title{
Miscommunication between Members Belonging to Different Subcultures
}

\author{
PhD Candidate, Roland Lami
}

Email: rolandlami@yahoo.com European University of Tirana

\section{Doi:10.5901/ajis.2013.v2n8p591}

\begin{abstract}
Based on theoretical perspective of some distinguishable authors in the field of sociology of communication, it will be intended to defend the hypothesis that non-communication between individuals or social groups during socializing processes produces problems related to psychosocial nature. Here, it is not the case that the actors of communication, such as "provider" and "recipient", face organic difficulties to capture or make their message accessible, but the fact that they do not understand the codes through which they transmit messages and therefore misunderstand the roles as a result of miscomprehending these messages. Exactly, this discrepancy between roles and codes of communication along the socialization process produces a state of "stagnation" of social conventions and confusion of roles. Analyzing the phenomenon in this perspective tends to contribute to the understanding of the Albanian context, as frequent demographic changes during last two decades, inside and outside the territory, have led to difficulties for some social groups or individuals to be integrated into new social realities.
\end{abstract}

Keywords: Typology. Identity, Code, Psychopathology, Autism, Transition

\section{Introduction}

According to Max Weber (1920), the analysis of social groups takes an important place in the sociological perspective of the world and especially of the mankind. From the author's point of view, there are double and reciprocal relationship and particular links between the individual and the social group, as well as certain rapports between the group identity and sorts of mentality and social conscientiousness. The collective subjectivity provides an identity to any of the social groups and at the same time, the nature of a social group offers its own special features to the mentality of different individuals.

To his judgment, the same social group, but appearing in different times and in different places of the social space, through particular history and lives, shapes its own social identity in different ways following different criteria. From this standpoint, it is worth studying typologies of social groups and interaction scale in the Albanian context in order to understand the situation and find out the barriers which may impede the normal development of their interaction.

The analysis of this dimension is of a particular importance in the Albanian context due to the fact that in the last two decades, we have faced a massive rural exodus and a considerable demographic concentration in some of the main cities of the country. As a consequence, this social mobility has led to the creation of a multicultural reality which is demonstrated during socializing processes. Precisely, these aspects are well demonstrated - better than in any other city of Albania - in the capital city, which has been noticeably "affected" by migratory movements of the two last decades.

\section{Migratory movements in suburban areas}

According to data published by the Statistical Institute of the Republic of Albania, during the years 1991 - 1999 the urban population is increase $11.2 \%$, reaching $47.1 \%$ (INSTAT, 2000:8), and this trend continues in the last decade, reaching 53.7\% in 2011 (INSTAT, 2011:16) Central regions (prefectures of Tirana and Durres) and coastal regions (the regions of Fier, Lezha) have become the main destination of this migration, while northeastern and southeastern regions are affected very little by internal population movements.

Tirana being a city with greater employment opportunities, education and entertainment, preferred more compared to Durres. According to the census in the Municipality of Tirana show dramatic increase in population from 238,057 inhabitants in 1989 to 343,078 in 2001. The same intensity observed during the period 2001 - 2009, where the city of 148,000 added in 2012 reaching number 702.380 inhabitants. However, it should be noted that in these areas over the past two decades have not only migratory movements from different areas of Albania moves towards the capital but also internally within the Tirana. Let's refer to data of year 2005 regarding this demographic dynamism. 
Based on official data (INSTAT,2006), it results that during that year 46.024 inhabitants coming from mountainous and lowland regions out of this district have settled there, 49.470 people have changed locations within Tirana district and 7.226 inhabitants have moved out of the district. This movement has occurred only in one year 2005. (INSTAT, 2005) How about the movements in 20 years? It is worth emphasizing that a detailed record of data for all the post communist era is still incomplete for reasons we already know. That is why we have chosen 2005, as one having the most complete data for migratory movements. But we cannot say that this year is the "peak" of demographic movements, because we know that higher intensity movements occurred during 1993 - 2000. Anyway, in this analysis we are not going to identify factors leading to such various demographic movements from one year to another, but we will analyze the psychosocial aspects which produce such realities from the viewpoint of communication sociology.

Turning back to the analysis, we may underline the fact that the origin of inhabitants having settled in the capital is: $39 \%$ coming from north and 38\% coming from south of the country (Karagumi \& Dumani, 2005). The majority of these inhabitants are settled in the suburban areas of Tirana and more concretely in local government unit no. 4 (Allias), unit no. 6 (Kombinat), unit no. 11 (Lapraka). From the development point of view, those areas are estimated as the poorest in Tirana district. Such estimation is related to several factors such as low level of consumption per capita, high coefficient of general poverty, high level of unemployment and low level of education. (Karagumi \& Dumani, 2009) Therefore, there are certain similarities between neighbors not only in terms of territorial point of view, but also whole demographic, economic and social developments. It is obvious that this entire panorama enables the approach of identities between the new inhabitants, but at the same time, as a consequence of this identity, it differentiates them from the autochthon population.

Under those new circumstances, many social groups that use to live in "silent" and "remote" nooks of society felt the need to be repositioned in the social structure. To some, this process is not easy at all, because they need to adapt themselves to new social and cultural realities and at the same time keep their tradition and norms of the past. As Fuga (2000:212) describes them with much realism, this dilemma interposes them between country and city, between rural life and urban life, between past and present, between survival and misery, between self-personification and transition towards another group identity. As a result, the moral criteria which inspire the moral norms of society, the behavior patterns of individuals and different groups of the society, go through a quick process of decomposition and disequilibrium. But, at the same time, there are cases of the consolidation of existing values because of the uncertainty of abandoning them.

Meunier \& Peraya (2009) view this duality through the normal functioning logic for each individual or social group that set up a special cohesion between them by excluding other groups considered as "foreign". They wish to be socialized, take part in the same actions, belong to the same group and at the same time, need to be differentiated, discriminated and excluded. In this case, exclusion is displayed in different levels varying from physical violence (physical exclusion of the other) to fine nuances, such as behavior, language, etc, while they display cohesion as a way of unifying their own ego with the group. Concerning this aspect, the above mentioned authors say: "The man, as an individual, wants to unify his ego with himself - this is narcissism, his ego with another person's ego in a couple - this is narcissism of the couple, and his ego with the others' ego - this is group narcissism" (Meunier \& Peraya, 2009:274). Following this dynamic, the social layer is fragmentized in opposite communities.

Edgar Morin (1977:178) holds the idea that each system is at the same time unitas multiplex, a link between the singular and plural, ensemble and types - according to cultures and historical moments. If we were to borrow a quote from Jacques Derrida, a postmodern philosopher, this link serves in many cases to create anybody's identity. More specifically, this author says: "Everyone's identity is built based on something different of him, as another's identity is." (Morin, 1977:54)

The communication certainly describes their effect in those movements and at the same time it helps or impedes the interaction between them in terms of accepting or refusing the identities they represent. Martin \& Nakayama (2010:108) argue that these identities emerge when messages of the communication are exchanged between individuals. And by free will they choose to negotiate, create together, reinforce or be challenged through communication. To them, communication represents an essential value in displaying their identities and creating new ones. Stefano Zecchimi shares the same opinion and outlines that: "Communication is always the origin of the society's identity; it is an expression of difference. Understanding this communication enables the knowledge of features of the society using it." (2006:9)

The attempt to be adapted to everyone's features during messages transmission and at the same time the interest to be differentiated to keep the identity become normal processes of communication. Time after time, these processes bring to light the lack of desire to put oneself in the others' position in order to understand their points of view in the final 
stage of compiling the message, because there is a conviction that it is not necessary. However, to Jean Piaget (1995), when there is a lack of such will, we come across problems in understanding the message and exclusive and marginalizing tendencies towards others. This warning of Piaget is supported by arguments of David Morley and Stuart Hall. According to these authors, there are problems with the meaning of the message itself, which does not depend only on the content of the message, but depends more on the scale of its interpretation and the latter is conditioned by the traditions in his background. In many cases, lack of acknowledging this tradition causes misunderstandings in the stage of deciphering the message.

In this semantic perspective, there is a conviction that the majority of words - symbols don't have any similarity with the object they represent. Eric Fromm writes: "What kind of link exists between the word "table" and the object "table"?(1998:11) Is there any relation to one another? Of course not, is the author's answer. The sole reason that this word symbolizes this object, is the fact that, as a result of a socializing period of time, the community has accepted that this object be called by this special name. Since childhood, this convention is fixed in out brain through repeated experience of hearing this word labeling this object. Such symbols are frequently designated as conventional ones. Thus, communicating does not mean only generating and distributing information, but it also means being attentive to the conditions in which the recipient receives, accepts, objects, reforms, restructures the message depending on his cultural, political philosophical horizon. In this case, communication bridges are consolidated between members who share the same communication codes and others that are different to them are excluded. Members of the group "weld" their unity, creating an entity in which each member is recognized and identifies himself, and at the same time noticeably weakens the relations with other different individuals.

That is why Paolo Alto (1951) considered communication "the matrix of all human activities" where the language, as one of its elements, has a primary importance. Thanks to it, people are able to transmit specific meanings to the other individuals included in the communication, while the latter have the possibility to interpret it and find out the answer based on those interpretations. Following the same line, George Ritzier says: "The meanings and the symbols offer distinguishable features to the social action (which contains a sole actor) and to the social interaction (which contains two or more actors included in mutual social actions)." (2009:371)

In our country, many subcultures that once were developed in areas and regions relatively separated and isolated, as a result of the domestic migration, are included in the same urban spaces. But we have to specify that the common physical space does not imply the unification of lifestyles, beliefs, traditions and behaviors carried from their past. The movement from isolated social areas with fixed moral codes or norms minimizes their capacities to perceive another world, which is different to the one they use to live. Once they come out of this reality for different reasons and are faced to unknown situations, they don't get involved in society or cut links to the exterior reality, living in their past. Certainly, it is possible for new meanings and new meaning lines. This behavior is related to the problems arising from the communication during the socializing processes. The capability of adoption in the interactive processes and more specifically, the misunderstanding or the lack of necessary codes is determined by the communication.

Inability to understand the previously unknown codes - or their misunderstanding - is simply related to a difficulty of organic kind, where for "the giver" as well as for "the receiver", it is impossible to decipher the meaning of their code or to know new ones. They don't understand the codes through which are transmitted the messages or don't have the appropriate coded to enable their transmission. As a result, their ideas are not properly articulated due to lack of authentic expressing words. In this case, using a figure of speech, says that we are in a situation when "the thought suffers". It tries to find what it needs, it murmurs, but it remains incomplete, defective and linguistically empty, because finding the correspondent word is not easy at all. The message can't to be fully expressed, because "the source", as well as "its receivers" do not own that codified system of signs, which enable its semantic content to be freely expressed. All this is influenced by what is rightly underlined by Pierre Bourdieu (1977:82), which is the cultural heritage. Thanks to this component, they are provided with a series of embedded schemes, which influence on the scale of perception and estimation of the social world, which is transmitted through communication. In most of the cases, they become victims of these schemes.

Under these circumstances, it is possible that the individual or specific groups become unities "withdrawn" society without a real communication with others. Thus, they are transformed into isolated unities, having contact only with themselves, inside their own world. (Fuga, 2010:276) In an individual level, the self is set in the center, obviously according to the ego of the person himself, and from here, there are efforts to introduce it to other people or to create a descriptive picture on the world surrounding us, starting from the self or putting ourselves in the center of it. The individual does not make any effort to recognize oneself through the other, as suggested by representatives of symbolic interaction (Cooley,1902. Mead,1934, Blumer,1969). Therefore, the man - trying to recognize oneself without any other intermediary 
agent - creates a much idealized imagination of his personality, because he puts himself in the center of the world. We can't exclude that cases of such psychosis can be manifested at group level.

For Jurgen Ruesch, (1998) forms of deviant behaviors vary depending on the ways the "other" is perceived. The author holds the opinion that "the communication network defines our psychiatric universe." (p.16) Symptoms of psychopathological disorders are very often caused by deformations and defaults in the functioning of the communication system, during the transmission of messages in three levels: communication of the individual with himself, communication with others and communication between large social groups. This is the infrastructure of relations created through transmitting messages, designated as "social matrix of communication", which serves to find the deepest roots of the phenomena and of the psychopathological disorders which induce and keep alive a large part of deviant behaviors.

During communication, people affected by such symptoms, the author says, do not dialogue with the others, but it seems like they talk to themselves, and thus lose what the psychotherapists call self-correcting capability. In a certain way, they pull back into themselves - into their own reality - and interrupt relations to the external reality. Therefore, paranoiac personalities arise from such situations. Mainly, these individuals with paranoiac personalities have a tendency to think that their ideas are the right ones and exclude other options. So, they do not take into consideration any other alternative during social discussions, but want at any price to impose to others and give authoritarian orders at home, at school etc. As soon as they are faced to the minimum objection of the others, such individual is inclined to get angry, quarrel or cause conflicts.

\section{Conclusions}

Referring it to the Albanian reality, we may say that individuals or social groups settled in large urban centers are frequently secluded within conventional symbols. The movement from isolated social areas with fixed moral codes or norms minimizes their capacities to perceive another world, which is different to the one they use to live. Once they come out of this reality for different reasons and are faced to unknown situations, they don't get involved in society or cut links to the external reality, living in their past.

Despite the desire to be socialized, take part in the same activities, belong to the same group, they need to become differentiated, discriminated and excluded because of the communication. In those circumstances, social conflicts not only are not mitigated, but on the contrary, they gain new forms which continue to be present even when old social disunions have lost their former ground. Now, new social conflicts take place in a society of interaction, differences and communication. Communication is one of the important components producing them. As it seems, values and criteria by which the individual tries to get to know himself, seeing himself as in a mirror, before becoming norms of point of views, are words of a specific language and have a signification only in the framework of their linguistic content. Those words, their meaningful content, the way we use them, are not defined by none of the individuals taken separately, or in his intimate solitude. They are social products created during a prolonged socializing process and it takes time to change them.

\section{References}

Baterson, G \& Ruech, J. (1998) Communication et societe, Seuil, Paris.

Bourdieu, P. (1999) On Television, London: New Press

Collins R. (1986) Weberian Sociological Theory, Cambridge: Cambridge University Press

James, C. (1992) Communication as Culture: Essay on Media and Society, London: Routledge

Hall, S. ( 1996) Critical dialogues in cultural studies, London:Routledge

Fuga, A (2010) Monolog Tirana: DUDAJ Press

Fuga. A. (2007) Rrota e mundimit, Tirane:DUDAJ Press

Fuga, A. (2000) Shoqeria Periferike, Tirane: ORA.

Karaguni, M \& Dumoni, B. (2009) Zhvillimet ne Tirane, "Refleksione mbi disa sfida, Revista Demografike. Tirane: ILAR

Karaguni, M \& Dumoni, B. (2005) Tirane, Reliev Demo - Ekonomik e Social, Revista Demografike. Tirane: ILAR

Magner, E. (2003) Le sociologie de la communication et des medias: Paris: Papirus Year

Martin, J. N and Nakayama, T. K. (2010) Intercultural Communication in Contexts. (5th ed). Boston: McGraw-Hill

Ritzer, G. \& Goodman, D. (2009) Sociological Theory ( 8th ed), New York: MacGraw-Hill Companies

Popullsia e Shqiperise, INSTAT, Tirane, 2006

Populllsia e Shqiperise, INSTAT, Tirane, 2005

Piaget, J. (1955) The Language and Thought of the Child, World Publishing Co. Snow

Zecchini, P. S. (2006) Dizionario dei sinonimi della lingua Italiana, stereotipa. University Oxford

Weber, M. (1920) The Theory of Social and Economic Organization, New York: The Free Press. 